\title{
Swim Training Reduces Metformin Levels in Fructose-Induced Insulin Resistant Rats
}

\author{
Kuei-Yu Chien ${ }^{1}$, Chi-Chang Huang ${ }^{1}, \mathrm{Ku}-\mathrm{Fu} \mathrm{Hsu}{ }^{2}$, Chia-Hua Kuo ${ }^{3}$, Mei-Chich Hsu ${ }^{1}$ \\ ${ }^{1}$ Graduate Institute of Sports Science, National Taiwan Sport University, Taoyuan, Taiwan, ROC. \\ ${ }^{2}$ Graduate Institute of Physical Education, National Taiwan Sport University, Taoyuan, Taiwan, ROC. \\ ${ }^{3}$ Laboratory of Exercise Biochemistry, Taipei Physical Education College, Taipei, Taiwan, ROC.
}

Received, September 10, 2011; Revised, December 12, 2011; Accepted, December 19, 2011; Published, December 21, 2011.

\begin{abstract}
Purpose: Regular exercise training and metformin medication are widely considered to increase insulin sensitivity and protect against type 2 diabetes, however, evaluating the effect of exercise training on the disposition and pharmacokinetics of metformin is unclear. Methods: We investigated the effect of a 4-wk swim training program ( $45 \mathrm{~min} /$ day, 5 days/wk) on the pharmacokinetics for the use of metformin in fructose-induced insulin resistant rats. Fructose-induced insulin resistant rats were assigned into two groups (n=6/group): swim training with metformin (SM), and non-swim training with metformin (CM). Blood samples were collected from $12 \mathrm{~h}$-fasted rats at baseline and at $0.25,0.5,0.75,1,2,3,4,6,8$, 10 , and $12 \mathrm{~h}$ after an oral glucose tolerance test (OGTT) with administration of a single dose of metformin $(450 \mathrm{mg} / \mathrm{kg})$. Results: Our study revealed that both glucose and insulin levels in the SM group were significantly lower than those in the CM group at 15 min following OGTT. The maximum concentration $\left(\mathrm{C}_{\max }\right)$ and area under the serum concentration-time curve (AUC) for the SM group were significantly lower than $\mathrm{CM}$ group. The apparent distribution volume $(\mathrm{Vd})$ and the time-averaged total body clearance $(\mathrm{CL})$ for the SM group were significantly higher than those for the CM group. There were no significant differences in the time to maximum concentration $\left(\mathrm{T}_{\max }\right)$ or the time to half-life concentration $\left(\mathrm{t}_{1 / 2}\right)$ between the two groups. Conclusions: Our data demonstrate that swim training reduces metformin serum levels.
\end{abstract}

This article is open to POST-PUBLICATION REVIEW. Registered readers (see "For Readers") may comment by clicking on ABSTRACT on the issue's contents page.

\section{INTRODUCTION}

Fructose is used extensively in carbonated beverages, baked goods, canned fruits, jams, and dairy products (1). The increasing consumption of fructose could play a potential role in the etiology of obesity and metabolic disease (2). The pathologic signs of insulin resistance in the fructose induced animal model resemble human type 2 diabetes mellitus $(3,4)$.

It is well established that exercise produces lower glucose and lipid profiles and decreased cardiovascular complications (5). Regular physical training has been found to improve insulin sensitivity in peripheral tissues for persons with impaired glucose tolerance and type 2 diabetes mellitus (6). Studies have shown that people with pre-diabetes (i.e., impaired glucose tolerance, IGT) can prevent or delay the development of type 2 diabetes mellitus (DM) by up to $58 \%$ through regular exercise (7). Exercise has been considered essential to diabetes management along with diet and medication (8).
Metformin was introduced for use in insulin-resistant states even before the development of hyperglycemia (9). Its effects include anti-hyperglycemic action, weight stabilization or reduction, with no risk for serious hypoglycemia and a countering of insulin resistance (10). Metformin has a narrow therapeutic window (11). It is an important to examine the factors that affect the narrow therapeutic window for medicine pharmacokinetics. Pregnancy (12), renal function (13), food intake (14), gastric emptying and gastrointestinal motility (15) have been reported to alter metformin pharmacokinetics. Our previous study showed that performing a single bout of swimming before metformin administration can improve insulin sensitivity and the rate of metformin absorption (16). However, there are major differences between acute and chronic exercise response following exercise

Corresponding Author: Mei-Chich Hsu; Graduate Institute of Sports Science, National Taiwan Sport University, 250, Wen Hua 1st Road, Kueishan, Taoyuan County 33301, Taiwan, ROC.E-mail: meichich@gmail.com 
stimulation. Acute exercise results in blood flow shunting away from the viscera and towards the muscle. Chronic exercise, on the other hand, results in an adaptation response that increases blood volume, increases fat free mass and reduces fat mass. Therefore, it is difficult to extrapolate the results from acute exercise to the effects from the physiological adaptations of regular exercise training. Given exercise training, there can still be different pharmacokinetic effects. Previous studies indicated that exercise training reduced the amount of $N$-acetylprocainamide concentration (17). Kim et al. indicated no difference in azosemide absorption in rats after treadmill running (18). Therefore, we extend knowledge from previous studies here. The purpose of this study was to examine the swim training effects on the glucose tolerance and pharmacokinetic parameters for metformin use.

\section{METHODS}

\section{Chemicals}

Metformin hydrochloride (Sigma, St. Louis, MO, USA), phenformin (Sigma), potassium dihydrogen phosphate (Merck, Darmstadt, Germany), acetic acid (Merck), dichloromethane (Merck), and high-performance liquid chromatography (HPLC)-grade acetonitrile (J.T. Baker, Phillipsburg, NJ, USA) were used. Double-deionized water was used throughout this study (Millipore Direct-Q5, Billerica, MA, USA).

\section{Animals}

Twelve male Wister rats, weighing 120-150 g, were purchased from the National Animal Laboratory of the National Science Council (NSC, Taipei, Taiwan, ROC). Rats were allowed to acclimatize to the facilities for 1 week before the studies began. The temperature of the animal room was maintained at $21-23{ }^{\circ} \mathrm{C}$, with a $12-\mathrm{h}$ light-dark cycle. Rats received normal rat chow (PMI Nutrition International, Brentwood, MO, USA) and water ad libitum. After the experiments, all animals were euthanized by over-exposure to carbon dioxide gas. This study was approved by the Animal Care and Use Committee of Taipei Physical Education College and conformed to the Guidelines for the Use of Laboratory Animals published by the Council of Agriculture, Executive Yuan, Taiwan.

\section{Study design and fructose-induced insulin resistance in rats}

After 1 week of familiarization, twelve rats were each fed a $10 \%$ fructose solution for 12 weeks (16). An oral glucose tolerance test (OGTT) was performed to evaluate the decreasing glucose concentration and insulin level by loading glucose $(1 \mathrm{~g} / \mathrm{kg})$. The area under the insulin curve (AUC insulin) and glucose (AUC glucose) were calculated using the trapezoidal rule. In addition to glucose and insulin levels, cholesterol, triglyceride, free fatty acids and blood pressure in a fasting state were also measured. The levels of serum cholesterol, triglyceride and free fatty acids were analyzed using a bioanalyzer (Kodak Ektachem DT60, Rochester, NY, USA). The systolic blood pressure (SBP) and distal blood pressure (DBP) were measured using the tail-cuff method using an electro-sphygmomanometer (model 179; Blood Pressure Analyzer IITC, Woodland Hills, CA, USA). Fructose solution administration group had significantly higher AUC insulin $(31.4 \pm 5.0$ vs. $4.9 \pm 9.3 \mathrm{~min} \cdot \mathrm{mg} / \mathrm{dl})$, AUC glucose $(1847.4 \pm 129.3$ vs. $1098.0 \pm 183.3$ $\mathrm{min} \cdot \mathrm{mg} / \mathrm{dl})$, triglycerides $(158.9 \pm 21.1 \mathrm{vs} .74 .1 \pm$ $6.7 \mathrm{mg} / \mathrm{dl})$ and systolic blood pressure $(137.5 \pm$ 2.1 vs. $128.0 \pm 3.9 \mathrm{mmHg}$ ) than those in the non-fructose treated normal control group after 12-weeks fructose solution administration. Therefore, the insulin-resistant condition was created in the rats (16).

According to the AUC insulin-matched results from the OGTT, rats with fructose-induced insulin resistance were assigned into two groups: (1) sedentary controlled with single dose of metformin administration (CM, n=6), and (2) swim training with single dose of metformin administration ( $\mathrm{SM}, \mathrm{n}=6)$. Rats in the SM group swam for $10 \mathrm{~min}$ per day for 2 days before beginning the experiment to familiarize them with the swimming environment. The water temperature was maintained at $34 \pm 1^{\circ} \mathrm{C}$. The SM group was made to swim for 45 min per day, while the $\mathrm{CM}$ group was placed in 4-cm-deep water for the same time. Swim training was performed for 4 wks, 5 days per week. The rats swam for 45 min without any loading treatment during the first week. Afterward, the rats swam with a lead tail weight, increasing the weight from $1 \%$ to $2 \%$ of the body weight during the $2-$ to 4-week period.

\section{Body weight and blood sampling}

Food was withheld for $12 \mathrm{~h}$ before the pharmacokinetic procedures. Body weights were measured before blood sampling. Blood samples $(0.5 \mathrm{~mL})$ were withdrawn first. The OGTT (with an oral glucose load of $1 \mathrm{~g} / \mathrm{kg}$ ) was performed, 
and metformin (450 $\mathrm{mg} / \mathrm{kg}, \quad$ p.o. $)$ was administered. Blood samples were collected into test tubes at $0.25,0.5,0.75,1,2,3,4,6,8,10$, and $12 \mathrm{~h}$. Samples were also used for blood glucose and serum insulin measurements between 0 and 2 h. Rats were re-fed normal chow and water after the second hour of blood sampling. Samples were centrifuged at $4000 \times \mathrm{g}$ for $5 \mathrm{~min}$, and serum was transferred to labeled tubes. All samples were stored at $-80^{\circ} \mathrm{C}$ until being assayed.

\section{Epididymal fat pad weight}

All rats were anesthetized with an intraperitoneal injection of pentobarbital sodium $(65 \mathrm{mg} / \mathrm{kg})$. The epididymal fat pad (EFP) was removed and weighed. Epididymal fat pad weights are highly correlated with overall body fat $(\mathrm{r}=0.95)$ as determined by carcass analysis (19). Therefore, EFP is as a marker to stand for adipose content of whole body. Relative EFP weight was calculated and presented as EFP weight/body weight $\times 100 \%$.

\section{Determination of metformin concentration}

Blood metformin concentrations were determined using the analytical method of Chien et al. (16). The serum $(50 \mu \mathrm{L})$ was acidified with $10 \mu \mathrm{L}$ of 1 $\mathrm{M}$ acetic acid and then deproteinated with $300 \mu \mathrm{L}$ acetonitrile. A $200 \mu \mathrm{L}$ volume of water was added, vortexed for $30 \mathrm{~s}$, and centrifuged at $12,000 \times \mathrm{g}$ for $5 \mathrm{~min}$. The supernatant was decanted into a fresh tube. This was further washed with $300 \mu \mathrm{L}$ dichloromethane, vortexed for $30 \mathrm{~s}$, and centrifuged at $12,000 \times \mathrm{g}$ for $5 \mathrm{~min}$. The upper aqueous layer $(20 \mu \mathrm{L})$ was injected into a HPLC system equipped with a Hypersil CPS column (3 $\mu \mathrm{m}, 250 \times 4.6 \mathrm{~mm}$ I.D.; Waltham, MA, USA). The flow rate was kept constant at $1 \mathrm{~mL} / \mathrm{min}$ and the temperature maintained at $40^{\circ} \mathrm{C}$. A mixture of acetonitrile and $0.01 \mathrm{M}$ potassium dihydrogen phosphate (40: 60, pH 5.5) was used as the mobile phase, with UV detection at $234 \mathrm{~nm}$. All concentrations were calculated from a standard metformin curve obtained from spiked serum samples. Phenformin was used as an internal standard.

\section{Glucose and insulin concentration}

A glucose analyzer (Lifescan, CA, USA) was utilized to determine the glucose concentration using the glucose oxidase method. Serum insulin was assessed with an Immunolite analyzer using the chemiluminescent method as described by the manufacturer (Diagnostic Products, Los Angeles, CA, USA).

\section{STATISTICAL ANALYSIS}

Pharmacokinetic data were analyzed using the WinNonlin program (vers. 1.1, Pharsight Corp., Mountain View, CA, USA) using a non-compartmental analytical method. The parameters included the area under the serum concentration-time curve (AUC), the apparent volume of the distribution $(\mathrm{Vd})$, the time-averaged total body clearance (CL), the time to the half life concentration $\left(t_{1 / 2}\right)$, the maximum concentration $\left(\mathrm{C}_{\max }\right)$, and the time to the maximum concentration $\left(\mathrm{T}_{\max }\right)$. All values were expressed as the mean \pm standard error (SE). Independent $t$-test was used to analyze the results. The statistical software used was SPSS 11.0 Statistics Program (Chicago, IL, USA). Values of $p<0.05$ were considered significant.

\section{RESULTS}

There was a slight trend toward less body weight in swimming trained-rats than in control rats ( $529 \pm 16$ versus $502 \pm 13 \mathrm{~g}$ ), but the difference was not statistically significant (Figure 1A). However, the relative epididymal fat pad weights in the SM group was significantly reduced by $15 \%$, as compared with those in the CM group $(p<0.05)$ (Figure 1B).

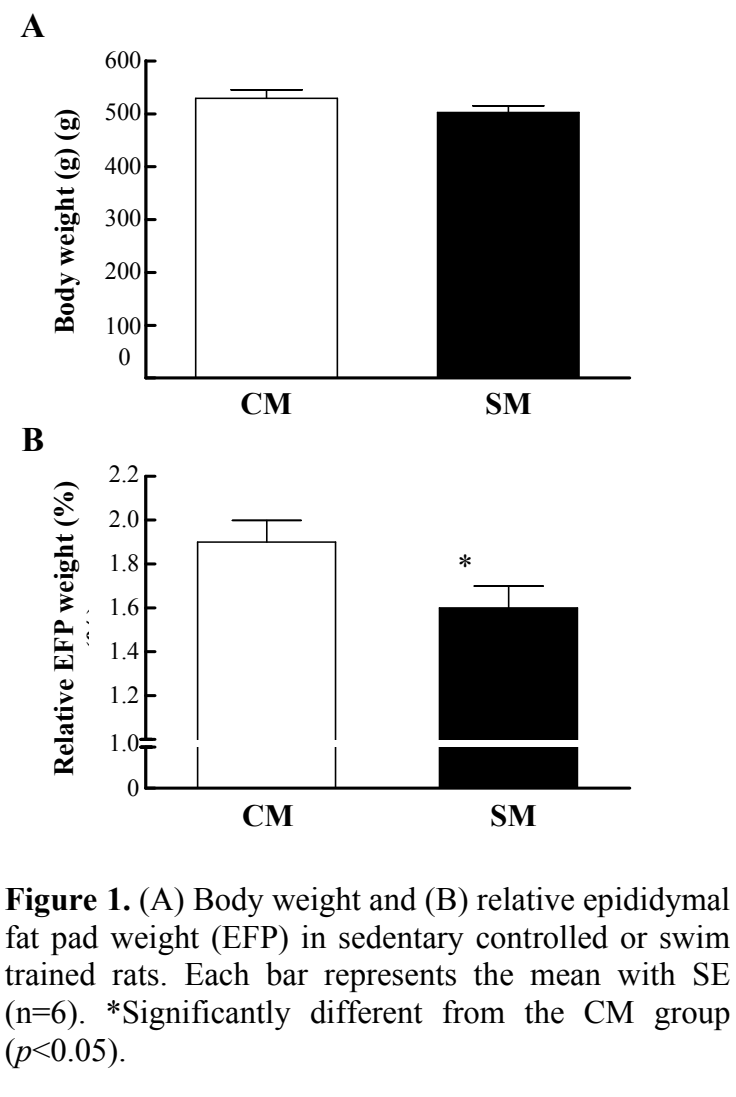


As shown in Figure 2, the glucose concentrations in the SM group were lower than those in the CM group at $15 \mathrm{~min}$ following OGTT. There were no significant differences between the two groups in serum glucose levels at $0.5,0.75,1$ and $2 \mathrm{~h}$ during OGTT. The Insulin concentrations in the SM group were also significantly lower than those in the CM group at $15 \mathrm{~min}$ and $1 \mathrm{~h}$ (Figure 3).

Serum metformin concentrations in the SM group were significantly lower than those in the
CM group from $30 \mathrm{~min}$ to $10 \mathrm{~h}$ (Figure 4). The maximum concentration and AUC for the SM group was significantly lower than that for the $\mathrm{CM}$ group. The apparent distribution $(\mathrm{Vd})$ volume and the time-averaged total body clearance (CL) for the SM group were significantly higher than that for the CM group. There were no significant differences in $T_{\max }$ and $t_{1 / 2}$ between the two groups (Table 1).

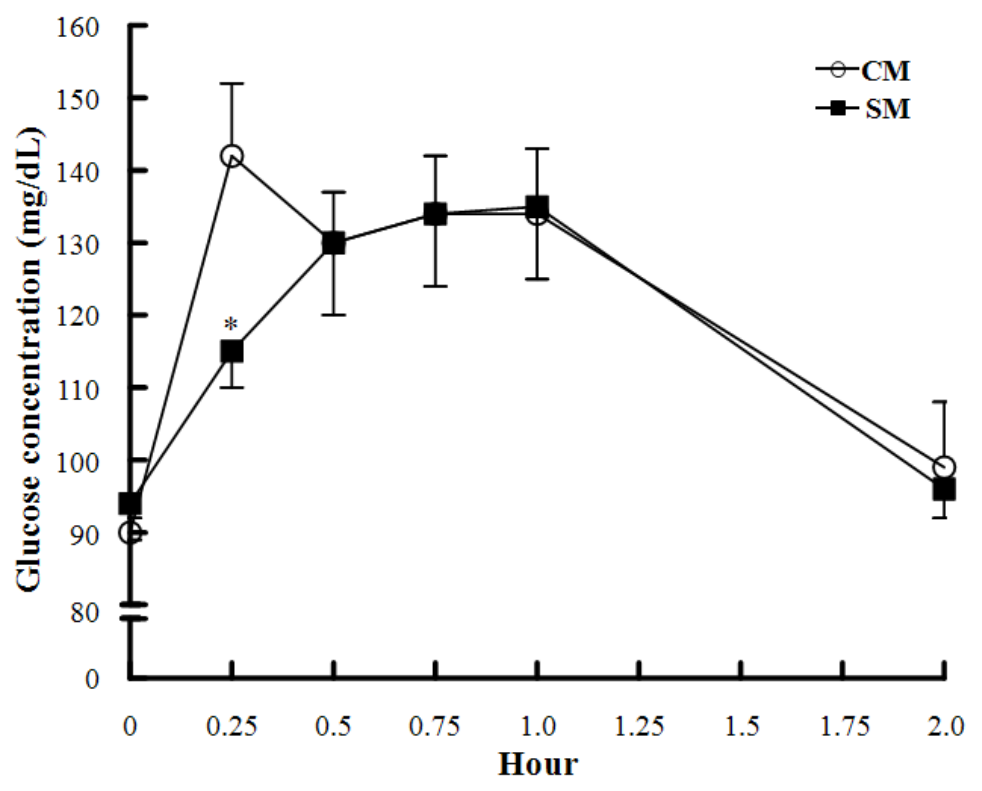

Figure 2. Glucose response curves during an oral-glucose-tolerance test in sedentary controlled (CM, open circle) or swim trained (SM, solid square) rats. Group SM swam for 45 min per day for 28 days. Each point represents the mean with SE $(\mathrm{n}=6)$. *Significantly different from the CM group $(p<0.05)$.

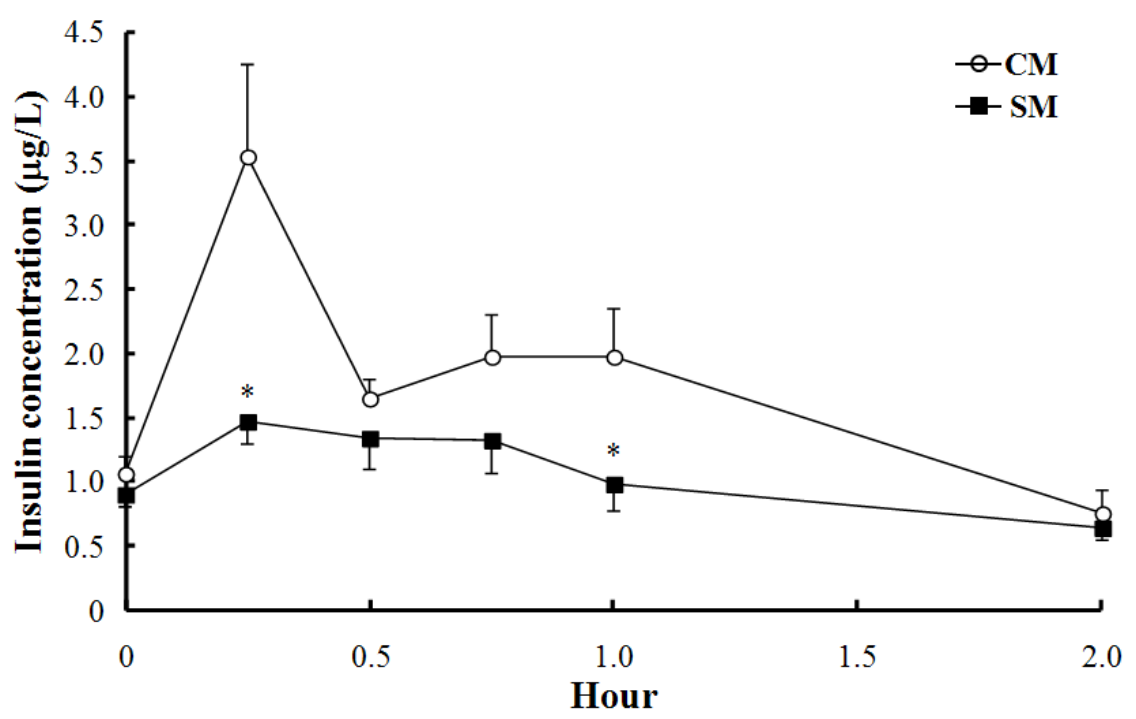

Figure 3. Insulin response curves during an oral-glucose-tolerance test in sedentary controlled (CM, open circle) or swim trained (SM, solid square) rats. Group SM swam for 45 min per day for 28 days. Each point represents the mean with SE ( $\mathrm{n}=6)$. * Significantly different from the $\mathrm{CM}$ group $(p<0.05)$. 


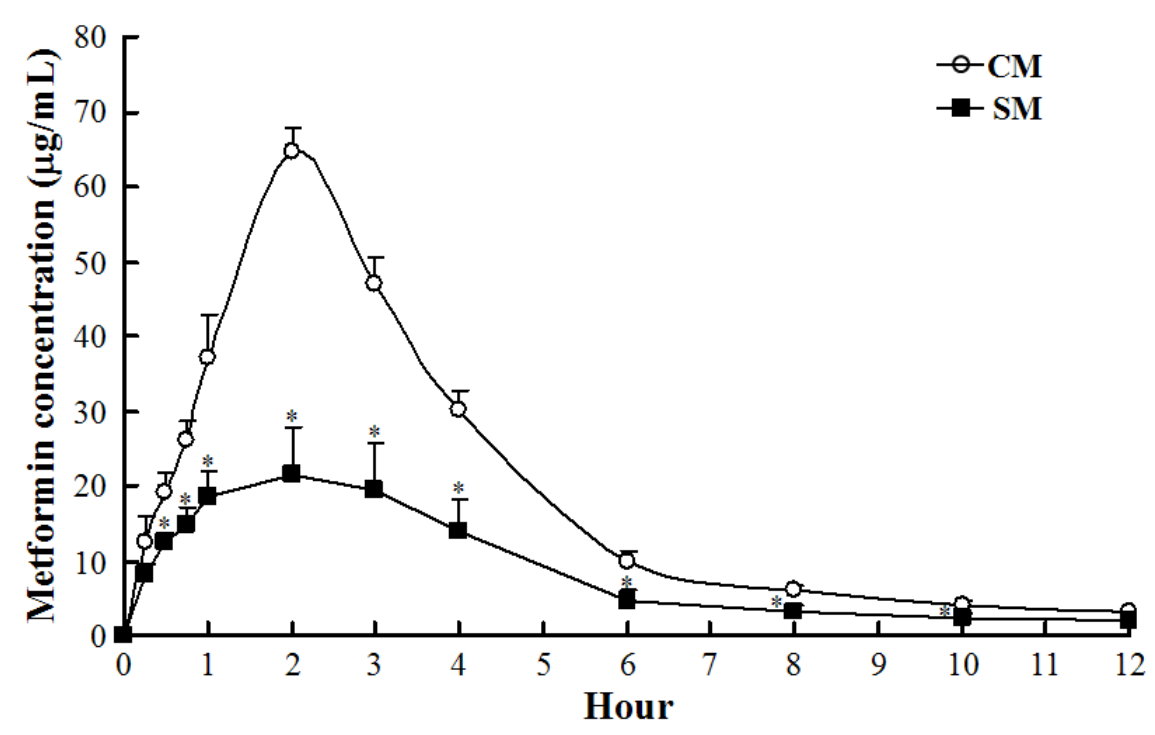

Figure 4. Mean serum concentration-time profiles for metformin after a single oral dose (450 $\mathrm{mg} / \mathrm{kg}) \mathrm{was}$ administered. Group SM (solid square) swam for 45 min per day for 28 days. Each point represents the mean with $\mathrm{SE}$ ( $\mathrm{n}=6$ ). *Significantly different from the CM group (open circle, $p<0.05$ ).

\begin{tabular}{|c|c|c|c|c|c|c|}
\hline Group & $\begin{array}{l}\mathbf{T}_{\max } \\
(\mathrm{hr}) \\
\end{array}$ & $\begin{array}{c}\mathbf{C}_{\max } \\
(\mu \mathrm{g} / \mathrm{mL})\end{array}$ & $\begin{array}{l}\mathbf{t}_{1 / 2} \\
(\mathrm{hr}) \\
\end{array}$ & $\begin{array}{c}\mathbf{A U C} \\
(\mathrm{hr} \times \mu \mathrm{g} / \mathrm{mL}) \\
\end{array}$ & $\begin{array}{c}\mathbf{V d} \\
(\mathrm{mL} / \mathrm{kg}) \\
\end{array}$ & $\begin{array}{c}\mathbf{C L} \\
(\mathrm{mL} / \mathrm{hr} / \mathrm{kg}) \\
\end{array}$ \\
\hline CM & $2.0 \pm 0.0$ & $64.7 \pm 3.2$ & $4.1 \pm 0.9$ & $232.3 \pm 14.3$ & $10.5 \pm 2.1$ & $1.8 \pm 0.1$ \\
\hline SM & $1.9 \pm 0.5$ & $26.9 \pm 7.1^{*}$ & $3.1 \pm 0.4$ & $109.5 \pm 28 *$ & $19.3 \pm 2.7 *$ & $4.7 \pm 0.9 *$ \\
\hline \multicolumn{7}{|c|}{$\begin{array}{l}\text { Group SM swam for } 45 \text { min per day for } 28 \text { days. } T_{\max } \text {, the time to maximum metformin concentration in } \\
\text { serum; } C_{\max } \text {, the maximum metformin concentration in serum; } t_{1 / 2} \text {, the elimination half-life; AUC, area } \\
\text { under the serum concentration-time curve; Vd, apparent volume of the distribution; CL, the } \\
\text { time-averaged total body clearance. Data are mean } \pm \mathrm{SE}(n=6) \text {. }{ }^{*} \text { Significantly different from the CM } \\
\text { group }(p<0.05) \text {. }\end{array}$} \\
\hline
\end{tabular}

\section{DISCUSSION}

Exercise can affect drug pharmacokinetics depending on factors such as the drug chemical properties, the route or timing of drug administration, and the mode of exercise (20-22). The major finding of this study was that swim training reduced the metformin accumulation. The maximum concentration and AUC for the SM group were significantly lower than that those for the CM group (Table 1).

In adding to the first-pass effect (23), reducing absorption content and increasing the rate of elimination would cause decreasing metformin levels. The blood flow, stomach-emptying rate and gastric intestinal mobility would affect the rate and extent of drug absorption (20). Blood flow is important in carrying absorbed drugs via systemic circulation. It is well known that blood is shunted away from the viscera (i.e. the stomach, liver, etc.) towards the muscles during moderate exercise. Study has shown that splanchnic blood flow redistribution will recover $60 \mathrm{~min}$ post exercise (24). In this study, the blood sampling period was in seated status (more than $20 \mathrm{hrs}$ after one session exercise training). Thus, the visceral blood distribution was not altered. Transit time through the gastrointestinal (GI) tract is the other factor that influences absorption. Study has shown that metformin absorption is increased when the gastrointestinal motility is slowed (15). Six to 13-week exercise training decreased GI transit time $(25,26)$. This could indicate that drug absorption in the gastrointestinal tract may be decreased. A decrease in bowel transit time during exercise may not allow adequate time for absorption, since drugs move through the gastrointestinal tract at a faster rate (27). Moreover, studies indicated that the inactive state 
increased bowel transit time (28). Therefore, we suggest that decreased absorption is probably due to reduced GI transit time.

Increasing the rate of elimination is the second reason for decreasing metformin levels. Drugs are eliminated by metabolism and excretion. It has been reported that metformin is metabolized via hepatic CYP2C11, 2D1 and $3 \mathrm{~A} 1 / 2$ (29). Studies have reported that exercise training may increase cytochrome P450 activity $(30,31)$. However, Kim et al. (21) and Ardies et al. (32) reported that exercise training may not alter CYPs activity. Thus, there is no evidence to show if exercise training can increase metformin metabolism via CYPs or not. There is a need for further investigation. Our study showed that swim training increased $\mathrm{CL}$ after metformin administration (Table 1). Generally, the kidneys can contribute to drug clearance via glomerular filtration, active secretion and tubular absorption. The principal mechanism of metformin elimination is active tubular secretion, a carrier-mediated system that has greater affinity for free-drug molecules compared to the plasma protein (33). Our study result is consistent with previous findings that exercise training increases clearance in minimal protein binding drugs (such as antipyrine) and elimination by active tubular secretion drugs (such as azosemide) $(18,34)$. This study showed that four weeks of exercise did increase the renal clearance for azosemide despite no change in renal function (18). Although we lack experimental evidence to support that exercise training increased CL by renal or non renal routes, we suggest that exercise training may increase renal CL. Exercise training enhanced azosemide clearance could be due to a considerable increase in intrinsic renal excretion of azosemide (18). Furthermore, metformin is transported by at least two organic cation transporters (OCT), OCT1 and OCT2. A recent study further demonstrated the contribution of human OCT to the renal tubular transport of metformin and indicated that OCT2 plays a dominant role for metformin pharmacokinetics (35). Zeibig et al. reported that there was a 7-fold up-regulation of OCT2 mRNA expression after 6-month training (36). Therefore, it may suggest that swim training increased the clearance of metformin possibly through the activation of OCT2 expression.

The area under the serum concentration-time curve reflected the total amount of drug content. Drug levels related to the efficiencies and side effects. The second major finding of this study was that swim training enhanced insulin sensitivity with lower metformin concentration (Fig 2, Fig 3 \& Table 1). Several studies showed that exercise training enhanced insulin sensitivity in health (37) and patients with Type 2 diabetes (38). Exercise training has a profound effect on the prevention and treatment of obesity and diabetes (39). In this study the results showed that swim training decreases EFP weight (Figure 2), which is consistent with a previous study (40). Adipose tissue is an endocrine organ and plays a prominent role in energy metabolism. Epididymal adipose tissue may contribute to the mechanism underlying the impaired glucose homeostasis and insulin resistance (41). The dysregulation of adipocyte function results in the development of a variety of metabolic and circulatory diseases (42). Adipocytokines are secreted from adipose tissue. It has been shown to influence insulin signaling, regulation of these cytokines and may play a role in the etiology of insulin resistance, obesity and diabetes by altering or influencing carbohydrate and/or lipid metabolism (39). Therefore, decreasing EFP is probably the other reason for increasing insulin sensitivity. Skeletal muscle is the target tissue for the peripheral disposal of glucose in response to a glucose challenge (43), and those effects persisted for at least $48 \mathrm{~h}$ after a single bout of exercise (44). It is well known that muscle contraction increases glucose uptake via stimulated the translocation of GLUT4 to the plasma membrane (45). Our data show that exercise training enhanced insulin sensitivity with metformin compared with only metformin administration. Chu et al. indicated the acute effect of metformin on glucose metabolism was an inhibition of hepatic glucose production and not a stimulation of glucose utilization (46). Furthermore, a previous study proved a single dose of metformin did not decrease the glucose area under the curve (16). Therefore, we suggest that the increasing insulin sensitivity was due to swim training and not the single dose of metformin administration. This study showed that swim training reduced metformin accumulation. A lower amount of drug concentration may reduce the metformin side effect (lactic acidosis). It is implicated that exercise may serve as a potential approach to decrease the systemic adverse effects of metformin.

The physico-chemical properties of the drug depend on transport processes and extent of plasma protein. The drug distribution in the body depends on tissue binding (47). The greater the amount of free drug available for distribution into 
the tissues, the greater the interaction with the receptors responsible for the pharmacologic response and drug elimination. The results showed the apparent distribution (Vd) volume for the SM group was significantly higher than that for the $\mathrm{M}$ group. The apparent distribution volume was calculated using the formula: $\mathrm{Vd}=\mathrm{Vp}+\mathrm{VT} \times \mathrm{fu} / \mathrm{ft}$, where $\mathrm{Vd}$ is the apparent distribution volume, $\mathrm{Vp}$ is the plasma volume, VT is the tissue volume, fu is the drug free fraction in the plasma and $\mathrm{ft}$ is the drug free fraction in the tissue. The increase in plasma water, tissue water and drug free fraction in the blood results in an increase in apparent distribution volume. Metformin is not a highly protein-binding drug. Therefore, the change in the drug free fraction in the blood would be minor. These results showed that body weight in the SM group was similar to that in the CM group (Figure1). Conversely, the percentage of EFP weight in the SM group was lower than that in the CM group (Figure 2). This implicated that there is more muscle tissue in the SM group than in the CM group, since the water content in muscle tissue is higher than that in adipose tissue. This study indicated that hydrophilic drug volume of distribution has a highly positive correlation with lean-body mass (48). Metformin is a hydrophilic drug. Thus, the exercise training enhanced the apparent drug distribution volume in the SM group probably via increasing muscle mass.

Concerns may be raised about the intestinal transit rate and protein levels of renal OCTs because we lack experimental and clinical evidence that addition with exercise training could decrease the GI transit time and enhance renal OCT2 mRNA level. Instead, we demonstrated that swim training can function to reduce metformin plasma concentrations in experimental animals. Whether the use of exercise training in general leads to reduced metformin blood levels needs further critical evaluation and investigation.

In conclusion, this study revealed that swim training decreases the metformin accumulation and has addictive effects on the glucose and insulin response to metformin administration in insulin resistant rats. It provides important information concerning the drug-exercise interaction and a model for the therapeutic indices to IGT or type $2 \mathrm{DM}$ patients.

\section{ACKNOWLEDGMENT}

This study was supported by the National Science
Council of Taiwan (NSC- 93-2413-H-261-001). We also thank Joel A. Newson for his careful editing of this manuscript.

\section{REFERENCE}

1 Hanover LM, White JS. Manufacturing, composition, and applications of fructose. Am J Clin Nutr, 1993; 58:724S-732S.

2 Bray GA, Nielsen SJ, Popkin BM. Consumption of high-fructose corn syrup in beverages may play a role in the epidemic of obesity. Am J Clin Nutr, 2004; 79:537-543.

3 Collino M, Aragno M, Castiglia S, Miglio G, Tomasinelli C, Boccuzzi G, et al. Pioglitazone improves lipid and insulin levels in overweight rats on a high cholesterol and fructose diet by decreasing hepatic inflammation. Br J Pharmacol, 2010; 160:1892-1902.

4 Catena C, Giacchetti G, Novello M, Colussi G, Cavarape A, Sechi LA. Cellular mechanisms of insulin resistance in rats with fructose-induced hypertension. Am J Hypertens, 2003; 16:973-978.

5 Batty GD, Shipley MJ, Marmot M, Smith GD. Physical activity and cause-specific mortality in men with Type 2 diabetes/impaired glucose tolerance: evidence from the Whitehall study. Diabet Med, 2002; 19:580-588.

6 Sato Y, Nagasaki M, Nakai N, Fushimi T. Physical exercise improves glucose metabolism in lifestyle-related diseases. Exp Biol Med, 2003; 228:1208-1212.

7 Tuomilehto J, Lindström J, Eriksson JG, Valle TT, Hämäläinen $\mathrm{H}$, Ilanne-Parikka $\mathrm{P}$, et al. Finnish Diabetes Prevention Study Group. Prevention of type 2 diabetes mellitus by changes in lifestyle among subjects with impaired glucose tolerance. N Engl J Med, 2001; 344:1343-1350.

8 Sigal RJ, Kenny GP, Wasserman DH. Castaneda-Sceppa C. Physical activity/exercise and type 2 diabetes. Diabetes Care, 2004; 27:2518-2539.

9 Davies MJ, Tringham JR, Troughton J, Khunti KK. Prevention of Type 2 diabetes mellitus. A review of the evidence and its application in a UK setting. Diabet Med, 2004; 21:403-414.

10 Scheen AJ. Clinical pharmacokinetics of metformin. Clin Pharmacokinet, 1996; 30:359-371.

11 Zolk O. Current understanding of the pharmacogenomics of metformin. Clin Pharmacol Ther, 2009; 86:595-598.

12 Hughes RCE, Gardiner SJ, Begg EJ, Zhang M. Effect of pregnancy on the pharmacokinetics of metformin. Diabet Med, 2006; 23:323-326.

13 Shenoy C. Metformin-associated lactic acidosis precipitated by acute renal failure. Am J Med Sci, 2006; 331:55-57. 
14 Sambol NC, Brookes LG, Chiang J, Goodman AM, Lin ET, Liu CY, et al. Food intake and dosage level, but not tablet vs solution dosage form, affect the absorption of metformin $\mathrm{HCl}$ in man. Br J Clin Pharmacol, 1996; 42:510-512.

15 Marathe PH, Wen Y, Norton J, Greene DS, Barbhaiya RH, Wilding IR. Effect of altered gastric emptying and gastrointestinal motility on metformin absorption. Br J Clin Pharmacol, 2000; 50:325-332.

16 Chien KY, Hsu KF, Lo HI, Pan RN, Kuo CH, Chen FA, et al. Effects of swimming on the pharmacokinetics and glucose tolerance of metformin in insulin-resistant rats. Biopharm Drug Dispos, 2008; 29:300-307.

17 Eddington ND, Adekoya F, Kharidia J. The influence of moderate and chronic exercise training on the pharmacokinetics of procainamide and N-acetylprocainamide. Biopharm Drug Dispos, 1998; 19:291-296.

18 Kim HJ, Lee AK, Kim YG, Bu SC, Kim SH, Yang $\mathrm{CH}$, et al. Influence of 4-week and 8-week exercise training on the pharmacokinetics and pharmacodynamics of intravenous and oral azosemide in rats. Life Sci, 2002; 70:2299-2319.

19 Stenger J, Bielajew C. Comparison of TOBEC-derived total body fat with fat pad weights. Physiol Behav, 1995; 57:319-323.

20 Khazaeinia T, Ramsey AA, Tam YK. The effects of exercise on the pharmacokinetics of drugs. J Pharm Pharm Sci, 2000; 3:292-302.

21 Kim, H. J., Lee, A. K., Kim, Y. G., Bu, S. C., Kim, S. H., Yang, C. H., et al. (2002). Influence of 4-week and 8-week exercise training on the pharmacokinetics and pharmacodynamics of intravenous and oral azosemide in rats. Life Sciences, 70(19), 2299-2319.

22 Persky, A., Eddington, N., \& Derendorf, H. (2003). A review of the effects of chronic exercise and physical fitness level on resting pharmacokinetics. Int $\mathrm{J}$ Clin Pharmacol Ther, 41(11), 504-516.

23 Choi YH, Kim SG, Lee MG. Dose-independent pharmacokinetics of metformin in rats: hepatic and gastrointestinal first-pass effects. J Pharm Sci 2006; 95: 2543-2552.

24 Pricher MP, Holowatz LA, Williams JT, Lockwood JM, Halliwill JR. Regional hemodynamics during postexercise hypotension. I. Splanchnic and renal circulations. J Appl Physiol, 2004; 97:2065-2070.

25 Cordain L, Latin RW, Behnke JJ. The effects of an anaerobic running program on bowel transit time. J Sports Med Phys Fitness, 1986; 26:101-104.

26 Koffler KH, Menkes A, Redmond RA, Whitehead WE, Pratley RE, Hurley BF. Strength training accelerates gastrointestinal transit in middle-aged and older me. Med Sci Sports Exerc, 1992; 24:415-419.
27 Lenz TL, Lenz NJ, Faulkner MA. Potential interactions between exercise and drug therapy. Sports Med, 2004; 34:293-306.

28 Liu F, Kondo T, Toda Y. Brief physical inactivity prolongs colonic transit time in elderly active men. Int J Sports Med, 1993; 14:465-467.

29 Choi, Y. H., \& Lee, M. G. (2006). Effects of enzyme inducers and inhibitors on the pharmacokinetics of metformin in rats: involvement of CYP2C11, 2D1 and $3 \mathrm{~A} 1 / 2$ for the metabolism of metformin. British Journal of Pharmacology, 149(4), 424-430.

30 Frenkl, R., Györe, A., \& Szeberényi, S. (1980). The effect of muscular exercise on the microsomal enzyme system of the rat liver. Eur J Appl Physiol Occup Physiol, 44(2), 135-140.

31 Boel, J., Andersen, L. B., Rasmussen, B., Hansen, S. H., \& Døssing, M. (1984). Hepatic drug metabolism and physical fitness. Clin Pharmacol Ther, 36(1), 121-126.

32 Ardies, C. M., Zachman, E. K., \& Koehn, B. J. (1994). Effect of swimming exercise and ethanol on rat liver P450-dependent monooxygenases. Med Sci Sports Exerc, 26(12), 1453-1458.

33 Tucker GT, Casey C, Phillips PJ, Connor H, Ward JD, Woods HF Metformin kinetics in healthy subjects and in patients with diabetes mellitus. $\mathrm{Br} \mathrm{J}$ Clin Pharmacol, 1981; 12:235-246.

34 Mauriz JL, Tabernero B, Garcia-Lopez J, Jorquera F, Villa JG, Gonzalez-Gallego J. Physical exercise and improvement of liver oxidative metabolism in the elderly. Eur J Appl Physiol, 2000; 81:62-66.

35 Kimura N, Masuda S, Tanihara Y, Ueo $\mathrm{H}$, Okuda M, Katsura $\mathrm{T}$, et al. Metformin is a superior substrate for renal organic cation transporter OCT2 rather than hepatic OCT1. Drug Metab Pharmacokinet, 2005; 20:379-386.

36 Zeibig J, Karlic H, Lohninger A, Dumsgaard R, Smekal G. Do blood cells mimic gene expression profile alterations known to occur in muscular adaptation to endurance training? Eur J Appl Physiol, 2005; 95:96-104.

37 Hulver MW, Zheng D, Tanner CJ, Houmard JA, Kraus WE, Slentz CA, et al. Adiponectin is not altered with exercise training despite enhanced insulin action. Am J Physiol Endocrinol Metab, 2002; 283:E861-E865.

38 Yokoyama H, Emoto M, Araki T, Fujiwara S, Motoyama K, Morioka T, et al. Effect of aerobic exercise on plasma adiponectin levels and insulin resistance in type 2 diabetes. Diabetes Care, 2004; 27:1756-1758.

39 Berggren JR, Hulver MW, Houmard JA. Fat as an endocrine organ: influence of exercise. J Appl Physiol, 2005; 99:757-764.

40 Wilmore JH, Despres JP, Stanforth PR, Mandel $\mathrm{S}$, Rice T, Gagnon J, et al. Alterations in body weight and composition consequent to $20 \mathrm{wk}$ of 
endurance training: the HERITAGE Family Study. Am J Clin Nutr, 1999; 70:346-352.

41 Soria A, D'Alessandro ME, Lombardo YB. Duration of feeding on a sucrose-rich diet determines metabolic and morphological changes in rat adipocytes. J Appl Physiol, 2001; 91:2109-2116.

42 Matsuzawa Y. The metabolic syndrome and adipocytokines. FEBS Lett, 2006; 580:2917-2921.

43 Henriksen EJ. Invited review: Effects of acute exercise and exercise training on insulin resistance. J Appl Physiol, 2002; 93:788-796.

44 Betts JJ, Sherman WM, Reed MJ, Gao JP. Duration of improved muscle glucose uptake after acute exercise in obese Zucker rats. Obes Res, 1993; 1:295-302.
45 Clark MG, Wallis MG, Barrett EJ, Vincent MA, Richards SM, Clerk LH, et al. Blood flow and muscle metabolism: a focus on insulin action. Am J Physiol Endocrinol Metab, 2003; 284:E241-E258.

46 Chu CA, Wiernsperger N, Muscato N, Knauf M, Neal DW, Cherrington AD. The acute effect of metformin on glucose production in the conscious $\operatorname{dog}$ is primarily attributable to inhibition of glycogenolysis. Metabolism, 2000; 49:1619-1626.

47 DiPiro, J.T.; Spruill, W.J.; Wada, W.E.; Blouin, R.A.; Pruemer, J.M., Concepts in clinical pharmacokinetics. 4th ed., American Society of Health Systems Pharmacists, Bethesda, MD, USA, 2005.

48 Morgan DJ, Bray KM. Lean body mass as a predictor of drug dosage. Implications for drug therapy. Clin Pharmacokinet, 1994; 26:292-307. 